\title{
Splenius Muscle Group
}

National Cancer Institute

\section{Source}

National Cancer Institute. Splenius Muscle Group. NCI Thesaurus. Code C53177.

Either of the two superficial, posterior vertebral muscles located in the neck and upper thorax: the splenius capitis (cranial portion) or splenius cervicis (cervical portion).

Together these muscles extend the head and neck. 